\title{
Multi-physics design of a truncated aerospike nozzle for an ammonium perchlorate solid fuelled hobby rocket
}

\author{
David Heath \\ School of Engineering, Computing and Mathematics \\ Oxford Brookes University \\ Oxford, UK \\ 15013672@brookes.ac.uk
}

\author{
Colin Bell \\ School of Engineering, Computing and Mathematics \\ Oxford Brookes University \\ Oxford, UK
}

\begin{abstract}
The performance of a rocket is highly dependent on the propulsive efficiency of its engine. Through the use of conventional bell and conical nozzles it is only possible to achieve high efficiency at a single external pressure design point whereas the aerospike concept is able to achieve high efficiency throughout the rockets flight regime. The external pressure of the nozzle of a hobby rocket is variable and primarily dependant on the velocity of the rocket due to aerodynamic bluff body effects. In this research a truncated aerospike nozzle was designed using the Angelino approximation method at the point of minimum external pressure, measured at 75 kPa. It was calculated that the increase in nozzle expansion performance would provide an increase in thrust of $0.325 \%$ when compared to the conventional Cesaroni conical nozzle operating in the same aft flow conditions. These promising results indicate that further work should be carried out on the design and integration of the nozzle into the body of the rocket, including nozzle cooling and ablation rates as well as nozzle mass reduction.
\end{abstract}

Aerospike, Truncated Aerospike, Angelino Approximation, Hobby Rocket

\section{INTRODUCTION}

Primary limiting factors of rocket performance are vehicle weight and thrust, both of which are impacted by propulsive efficiency. High efficiency in transforming the chemical potential energy of the propellant into jet energy effectively increases the energy density of the propellant and is therefore a highly effective method of increasing performance margins. A pivotal limitation in the propulsive efficiency of a rocket is the efficiency at which the nozzle transforms the potential energy present in the post-combustion exhaust into kinetic energy responsible for the momentum transfer to the vehicle via the supersonic Prandtl-Meyer expansion mechanism. Therefore, optimum efficiency in this transformation process is highly desirable. Conventional bell and conical nozzles are only able achieve high efficiency at a single external pressure design point. This is conventionally the highest external pressure experienced by the nozzle due to concerns of exhaust flow separation leading to nozzle instability $[6,8]$.
External pressure of the nozzle of a hobby rocket is variable and dependant on the velocity of the rocket due to aerodynamic bluff body effects. Through successive expansion and compression shockwave interaction with the exhaust, the aerospike nozzle is able to operate efficiently from launch to maximum velocity. Reference [2] demonstrated this in 2004 and stated that the gas properties of the motor exhaust used in their research were $381.9986 \mathrm{~J} / \mathrm{Kg} \mathrm{K}$ for the specific gas constant and 1.194 for the ratio of specific heats. These values were from a modified version of the $150 \mathrm{~mm}$ Cesaroni ammonium perchlorate motor. This motor was manufactured without aluminium agglomerate so as to avoid the complexities of multiphase flow through the nozzle. It is important to note that the motor used in the current study, a Cesaroni two grain Blue Streak, has an aluminium agglomerate additive however the proportion of this additive is not quantified by Cesaroni due to the commercial nature of this motor. The gas properties reported by [2] in conjunction with the thrust and mass flow rate obtained from the Cesaroni Pro 29 Catalogue [3] allowed calculation of the motors' internal gas properties by [4]. These are shown in Table 1.

TABLE 1: Cesaroni Two Grain Blue Streak Motor characteristics [4]

\begin{tabular}{|c|c|}
\hline Variable & Value \\
\hline Chamber Pressure $(\mathrm{Pa})$ & 4958168.39 \\
\hline Chamber Temperature $(\mathrm{K})$ & 2029.63 \\
\hline Thrust $(\mathrm{N})$ & 83.1 \\
\hline Mass Flow Rate $\left(\mathrm{Kgs}^{-1}\right)$ & 0.0396 \\
\hline
\end{tabular}

Designing a nozzle traditionally relies on the method of characteristics applied to the Prandtl-Meyer expansion theory, proposed by [5]. This is complex and [1] provides a simplified mathematical approximation of the method of characteristics applied to an aerospike nozzle known as the Angelino approximation. Reference [1] states that his method produces a nozzle geometry that closely approximates the geometry produced by the method of characteristics, this has however been challenged by [7] due to the increased curvature of the expansion spike when compared to the two dimensional kinetics model used in the work done by [7]. An increased 
curvature represents a loss in nozzle expansion efficiency which should be borne in mind when discussing relative nozzle efficiencies of the designed aerospike and the standard conical nozzle.

\section{Methodology}

Fundamental motor properties for the Cesaroni two grain blue streak motor were obtained from the work done by [4] using the general equations of thrust, gas velocity and Mach number presented in Rocket Propulsion Elements [8] as well as the gas properties presented in the work done by [2]. To introduce the aspect of multi-physics optimisation of the nozzle design the external experienced pressure was found using a StarCCM + simulation of the rocket in the work done by [4]. Thus a pressure of $75 \mathrm{kPa}$ was found at a maximum velocity of $300 \mathrm{~ms}-1$. This is the minimum pressure at the base of the rocket due to bluff body effects, the dominant pressure effect due to negligible pressure change over the rockets maximum operating altitude of two kilometres. As at this design point the expansion ratio is much less than the maximum expansion ratio a truncated aerospike design was sought in order to reduce nozzle mass.

Using the work done by [1] a Matlab code was developed to model the ideal expansion geometry of the spike. This relies on iteratively changing the Match number of the exhaust gas and computing the location of the surface impingement of approximated characteristic lines. The Mach number of the exhaust is varied from one (at the nozzle throat) to the exit Mach number calculated earlier from the ideal expansion ratio. The ideal expansion ratio is calculated from the pressure ratio at the design point of the nozzle. This is the ratio of external experienced pressure to the pressure entering the converging diverging nozzle.

\section{RESULTS AND DISCUSSION}

This nozzle design shows an increase in thrust of $0.325 \%$ with relation to the conical nozzle designed by Cesaroni but the aerospike concept holds significantly more promise if used at higher pressure ratios as is shown by Fig. 1. This is especially the case with larger rockets as these would reach higher velocities and altitudes, thus experiencing a greater pressure change. This would allow greater use of the variable expansion ratio and greater efficacy of the aerospike with relation to a conventional conical or bell nozzle. While Fig. 1 is limited to displaying the conical nozzle present on the current motor it must be stated that the aerospike is able to make more efficient use of the base of the rocket for effective exhaust expansion [6]. This is true regardless of the rocket size and as such a similar graph could be drawn for most propulsion systems comparing a conventional nozzle to the corresponding aerospike. Thus the limitation on when aerospike nozzles are used becomes a question of nozzle mass. This is a complex topic that must be addressed for each propulsion system independently but in general it is postulated that the benefits offered by the aerospike nozzle concept grow as the propulsion system increases in size.

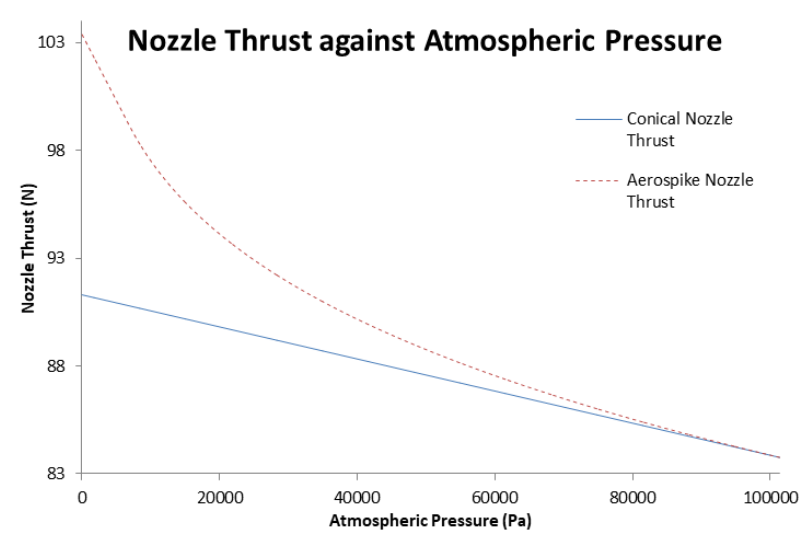

Fig. 1. A graph of nozzle thrust against atmospheric pressure showing the large improvements in thrust achievable by the aerospike at higher pressure ratios.

\section{CONCLUSIONS}

An efficient nozzle has been designed using the Angelino approximation method [1] utilizing external flow conditions to describe an appropriate pressure ratio design point and back calculation of the motor internal gas properties. This has been shown to have an increase of thrust of $0.325 \%$ when compared to the conventional conical nozzle but shows greater promise if designed for higher pressure ratios, in particular when operating in very low pressure environments. It is therefore recommended that further research be done on integrating the aerospike concept into launch vehicles. The increased performance and efficiency this would bring could have drastic effects on the industry.

\section{REFERENCES}

[1] Angelino, G. (1964) 'Approximate Method for Plug Nozzle Design' AIAA Journal, Vol. 2, No. 10, pp. 1834-1835, DOI: 10.2514/3.2682

[2] Bui, T., Murray, J., Rogers, C., Bartel, S., Cesaroni, A. and Dennett, M. (2005) 'Flight Research of and aerospike Nozzle Using High Powered Solid Rockets' 41st AIAA/ASME/SAE/ASEE Joint Propulsion Conference \& Exhibit 10 - 13 July 2005, Tucson, Arizona

[3] Cesaroni Technology Incorporated, (2010) Pro29 2010 Catalog - V1.0, Available at: http://www.pro38.com/pdfs/Pro29Catalog.pdf (Accessed on $17 / 10 / 2018$ )

[4] Heath, D. (2019) Design of a Competition Capable Hobby Rocket. Unpublished BEng Thesis, School of Engineering, Computing and Mathematics, Oxford Brookes University.

[5] Rao, G. (1961) 'Spike Nozzle Contour for Optimum Thrust', Planetary and Space Science, Vol. 4, pp. 92-101, DOI: 10.1016/00320633(61)90125-8

[6] Ruf, J. and McConnaughey, P. (1997) 'The Plume Effects Behind Aerospike Nozzle Altitude Compensation and Slip Stream Effect', $33^{\text {rd }}$ Joint Propulsion Conference and Exhibit, 06-09 July, Seattle, Washington

[7] Simmons, J. (2014) Design and Evaluation of Dual-Expander Aerospike nozzle Upper Stage Engine. PhD Thesis, Air Force Institute of Technology, Graduate School of Engineering and Management.

[8] Sutton, G and Biblartz, O. (2017) Rocket Propulsion Elements, Ninth Edition. Oxford: John Wiley and Sons Inc. 